\title{
Evaluation of Dermatological Adverse Drug Reaction in the Outpatient Department of Dermatology at a Tertiary Care Hospital
}

\author{
Dimple Gohel ${ }^{1}$, Sandip Kumar Bhatt ${ }^{\star 1}$ and Supriya Malhotra ${ }^{2}$ \\ ${ }^{1}$ Department of Pharmacology \& Clinical Pharmacy, K. B. Institute of Pharmaceutical Education and Research, Gh-6, Sector-23, \\ Gandhinagar, Gujarat-382023 \\ ${ }^{2}$ Department of Pharmacology, Smt. NHL Municipal College, Ellisebridge, Ahmedabad, Gujarat- 380006
}

\begin{abstract}
Background: The burden of dermatological Adverse Drug Reactions (ADRs) is resulting into switching or discontinuation of drug as well as medication non-adherence. Active search is essential for evaluating, managing, reporting ADRs and strengthening the activity of pharmacovigilance of the country. The purpose of the study was to evaluate causality, severity and preventability of Dermatological ADRs. Method: A prospective, observational study was carriedout over a period of six months at Out Patient Department of Dermatology, Sheth V.S. hospital, Ahmedabad with diagnosed dermatological ADRs. The suspected ADRs were evaluated for causality by WHO-UMC causality and Naranjo's scale, severity by Hartwig and Siegel scale, and preventability by Schumock and Thornton criteria. The agreement between causality scales was obtained by Cohen's Kappa test. Result: Total of 51 patients were enrolled with 74 suspected ADRs. The incidence of dermatological ADR was $3.78 \%$. Most commonly manifested ADR was rash $(26.67 \%)$. Total 97 drugs were suspected. Maximum incidence of dermatological ADRs were observed with antimicrobial agents $(43.30 \%)$ followed by non-steroidal antiinflammatory drugs $(26.80 \%)$, possible $(54.64 \%)$ and $35(36.08 \%)$ probable ADRs by WHO-UMC scale. Naranjo's scale showed most cases of probable $(74.23 \%)$. ADRs were of moderate severity $(98.97 \%)$ and definitely preventable $(72.16 \%)$. The causality scales showed 'slight agreement' with kappa value 0.012. Conclusion: Dermatological adverse drug reactions were a common occurrence and awareness about them was found to be essential for early detection and prevention. The healthcare system can promote the spontaneous reporting of dermatological ADR top Pharmacovigilance centre's for ensuring safe drug use and patient care.
\end{abstract}

Keywords: Cutaneous adverse drug reactions, Pharmacovigilance, Epidemiology Ahmedabad.

\section{INTRODUCTION}

Drugs, no matter how safe and efficacious, are coupled with in escapable risk of adverse reactions. Adverse Drug Reactions (ADRs) are considered as one among the leading causes of morbidity and mortality. ${ }^{1}$
Adverse Drug Reactions are major problem of drug therapy. According toWHO, an adverse drug reaction is defined as "a response to a drug that is noxious and unintended and occurs at doses, used in man for prophylaxis, diagnosis, or therapy of a disease or for modification of physi-
Submitted Date : 15-06-2014 Accepted Date : 03-09-2014

DOI: $10.5530 /$ ijopp.7.3.9

Address for correspondence: Dr. Sandipkumar Bhatt Department of Pharmacology \& Clinical Pharmacy, K. B. Institute of Pharmaceutical Education and Research, Gh-6, Sector-23, Gandhinagar, Gujarat Phone: 079-23249069 E-mail: sunrisedeep78@ rediffmail.com

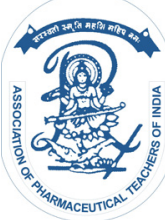

www.ijopp.org 
ological function. ${ }^{2}$ Adverse Drug Reactions may also result in diminished quality of life, increased physician visits, hospitalizations, and even death. The incidence of dermatological ADRs among in-patients in developed countries ranges from $1-3 \%$ whereas in developing countries such as India it is $2-5 \%$. The incidence of drug-induced adverse skin reactions is found to be $2-15 \%$ at a dermatology outpatient setting. ${ }^{3}$

In many countries ADRs rank among the top 10 leading causes of mortality and India is one of them. There is a need to study ADRs and ADRs reporting to minimize the risk of medicines. Pharmacovigilance is the study of the safety of drugs marketed drugs examined under the practical conditions of clinical use in large populations. ${ }^{4}$ Early detection, evaluation and monitoring of ADR are essential to reduce harm to patients and thus improve public health. ${ }^{5}$

Pharmacists play an important role in the field of medicinal drugs including in the scientific field dealing with the safety of drugspharmacovigilance. ${ }^{6}$ Hospital/ clinical pharmacists also have a greater role to play in the area of pharmacovigilance to strengthen the national pharmacovigilance program. ${ }^{7}$

The burden of ADRs is resulting into switching or discontinuation of drug as well as medication non-adherence. Little information is available about dermatological adverse drug reactions associated and it's reporting in routine clinical practice in Gujarat especially in Ahmedabad. Therefore, the attempt has been made to explore dermatological ADRs.

\section{MATERIAL AND METHOD}

It was a prospective, observational, non-interventional, cross-sectional study carried out at Out Patient Department of Dermatology at Sheth V. S. Hospital, Ahmedabad over a period of six months (December 2013-April 2014). The study was approved by K.B. Independent Ethics Committee of K.B. Institute of Pharmaceutical Education and Research.

The inclusion criteria of the study were patients of all age groups with both genders, patients presenting in Out Patient Department (OPD) of dermatology, patients on another medicines at first visit, patients coming for follow-up visit, patients with any disease and co-morbid condition and patient who had been hospitalized due to dermatological ADR referred by OPD of dermatological physician. The patient diagnosed with dermatological ADR had been enrolled. Pregnant women and nursing mothers were excluded. Demographic data like patient initial, hospital number, age, sex, marital status, medical history, medication history, surgery history, allergies, herbal and cosmetic use had been recorded on the case record form. The prescription given to the patient including the drug prescribed, dose, frequency and duration of the treatment had noted on the case record form. The findings related to ADR also added into CDSCO's ADR reporting form. The management of ADR was recorded in case record form. Causality of ADRs was evaluated by WHO-UMC assessment scale and Naranjo's scale. Severity of ADRs was evaluated by Hartwig and Siegel's scale. Preventability of ADRs was evaluated by Schumock and Thornton's criteria. Statistical analysis was carried out by using SPSS Version 22.0. Descriptive analysis had been represented in mean with standard deviation, frequency, percentage, range to present preliminary data. Fisher Exact test was used to test level of significance at $95 \%$ confidence interval and $5 \% \alpha$. Result was considered as significant when $\mathrm{p}<$ 0.05 obtained. Agreement between WHO-UMC causality assessment and Naranjo's scale was established by Cohen's kappa test.

\section{RESULT}

51 patients with 74 suspected Adverse Drug Reactions were screened and enrolled for the study based on previously discussed inclusion and exclusion criteria. From these $28(54.90 \%)$ males and $23(45.09 \%)$ females as sample with ratio of male: female 1.21:1. The incidence of dermatological ADR was $3.78 \%$. The mean age of sample was $38 \pm 19.73$ years ranging from 0.8 to 85 years. The most commonly reported dermatological ADRs were rash $(\mathrm{n}=20,26.67 \%)$ cases followed by prurit is $(n=8,10.67 \%)$, urticaria $(n=8,10.67 \%)$ (Figure 1$)$.

The most common suspected drug class showing highest numbers of ADR were antimicrobial agents $(n=42,43.30 \%)$, followed by $(n=26,26.80 \%)$ of NSAIDs(Figure 2). From the total 97 suspected drug, the most frequent suspected drugs were paracetamol $(\mathrm{n}=15,15.46 \%)$, amoxicillin $(\mathrm{n}=9,9.28 \%)$, diclofenac $(n=6,6.19 \%)$, cefixime $(n=5,5.15 \%) .4$ individual cases of ibuprofen, nevirapine, phenytoin, prednisolone. $3(3.09 \%)$ cases of gentamicin, pyrazinamide, $2(2.06 \%)$ cases of azithromycin. Paracetamol showed highest number of suspected ADRs followed by amoxicillin (Table 1).

There were four different actions taken against the suspected drug which were drug discontinuation, drug replaced, dose reduction and medication given for the management of ADRs (Table 2). The total numbers of medicines given for management of ADR were 238. Among them, most common drug prescribed was chlorpheniramine in 51 cases, followed by calamine lotion in 22 cases, ranitidine in 18 cases, Azithromycin in 16 cases, liquid paraffin on 14 cases. 


\section{Table 1: Most common suspected drug with reaction details}

\section{Suspected Drug}

Paracetamol

(NSAIDs)

Amoxicillin

(Antimicrobial)

Diclofenac

(NSAIDs)

Cefixime

(Antimicrobial)

Ibuprofen

(NSAIDs)

Nevirapine

(Antimicrobial)

Phenytoin

(Antiepileptic)

\section{Reaction details}

Frequencyn (\%)

$15(15.46 \%)$

Rash (8), Pruritis (3), Angioedema (2), Facial edema (1), Urticaria (1)

$9(9.28 \%)$

Urticaria (3), Rash (2), Maculopapular rash (2), Pruritis (1), Fixed Drug Eruption (1)

$6(6.19 \%)$

Urticaria (2), Rash (2), Maculopaular rash (1), Itching (1)

$5(5.15 \%)$

Rash (2), Pruritis (1), Urticaria (1), Facial edema (1)

$4(4.12 \%)$

Angioedema (1), Fixed Drug Eruption (1), Urticaria (1), Rash (1)

$4(4.12 \%)$

Oral lesions (2), Rash (1), Maculopapular rash (1)

$4(4.12 \%)$

Table 2: Action taken against suspected drug

\begin{tabular}{|c|c|c|}
\hline \multicolumn{2}{|c|}{ Action against suspected drug } & \multirow{2}{*}{$\begin{array}{c}\text { Frequency (n,\%) } \\
65(67.01 \%)\end{array}$} \\
\hline & Yes & \\
\hline Drug aiscontinuation & No & $32(32.99 \%)$ \\
\hline \multirow{2}{*}{ Drug replacement } & Yes & $94(96.91 \%)$ \\
\hline & No & $3(3.09 \%)$ \\
\hline \multirow{2}{*}{ Dose reduction } & Yes & 95 (97.94\%) \\
\hline & No & $2(2.06 \%)$ \\
\hline \multirow{2}{*}{ Medication given for ADR } & Yes & $4(4.12 \%)$ \\
\hline & No & $89(95.88 \%)$ \\
\hline
\end{tabular}

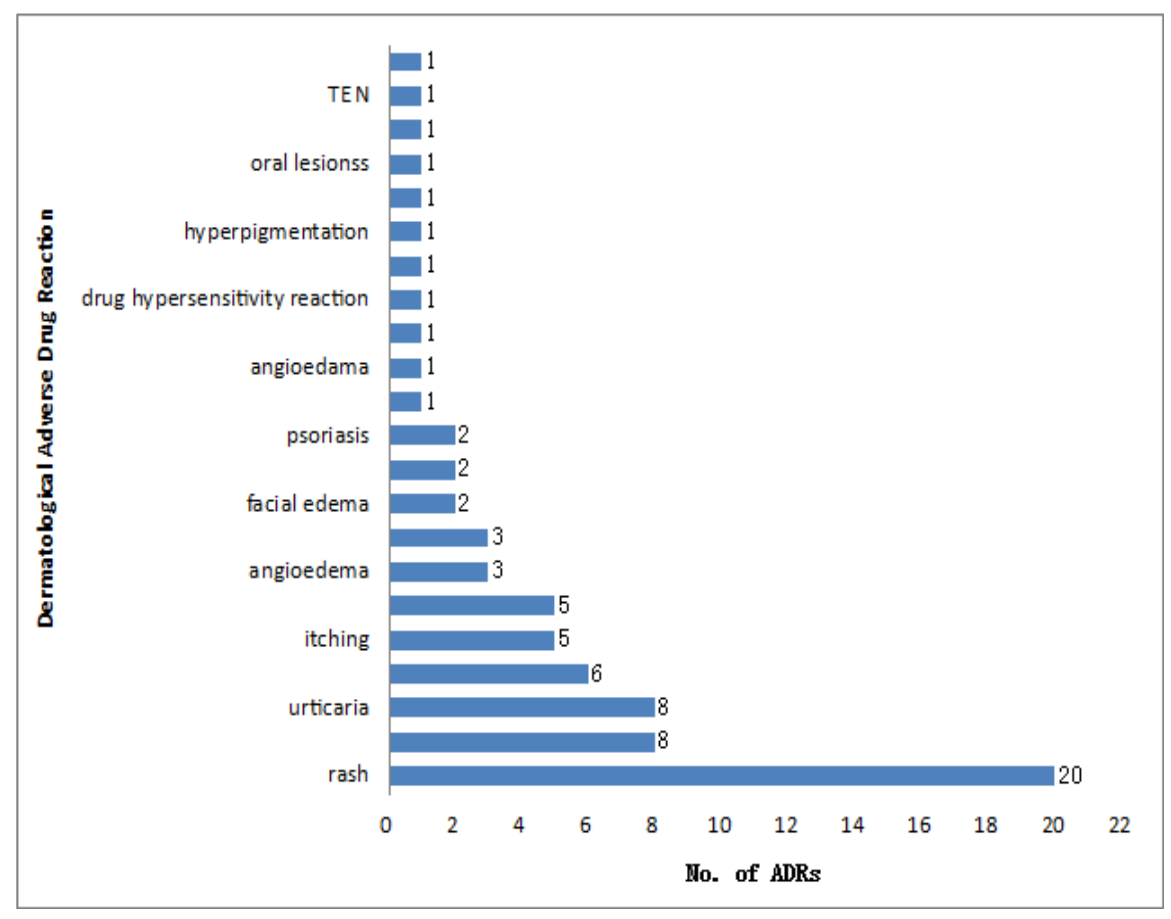

Figure 1: Total numbers of suspected dermatological ADRs 


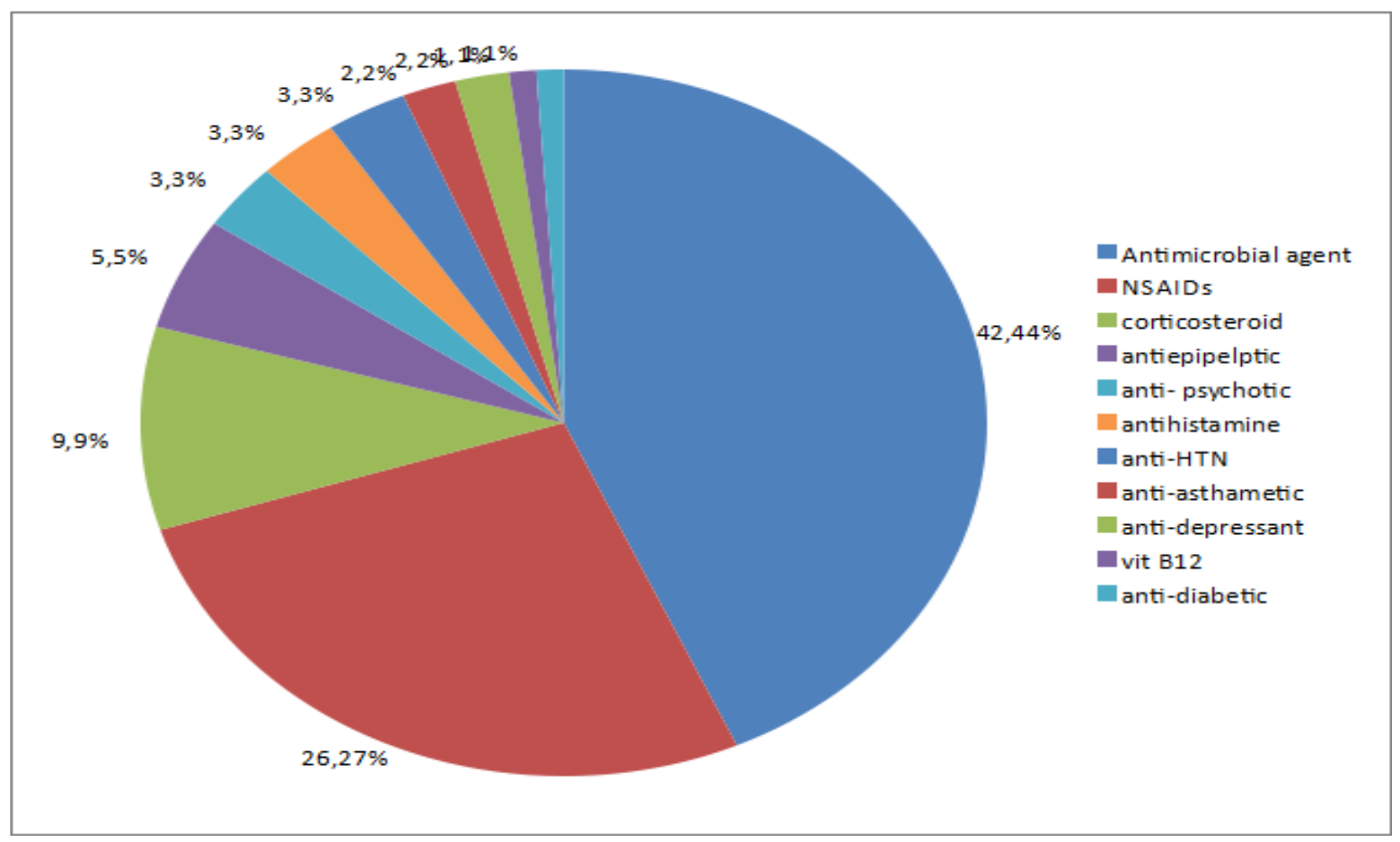

Figure 2: Therapeutic class of suspected drug

Out of 72 dermatological ADRs, the 53 numbers of cases found to be possible by WHO-UMC assessment scale (Figure 3) where as 72 numbers of cases found to be probable by Naranjo's scale (Figure 4). 2 dermatological ADRs were classified as mild while 95 dermatological ADRs were found to be moderate
(Figure 5). In case of preventability of dermatological ADRs, 70 were definitely preventable where as 27 were probably preventable (Figure 6).Comparison of WHO-UMC and Naranjo's causality had shown 'slight agreement' with kappa value 0.012.

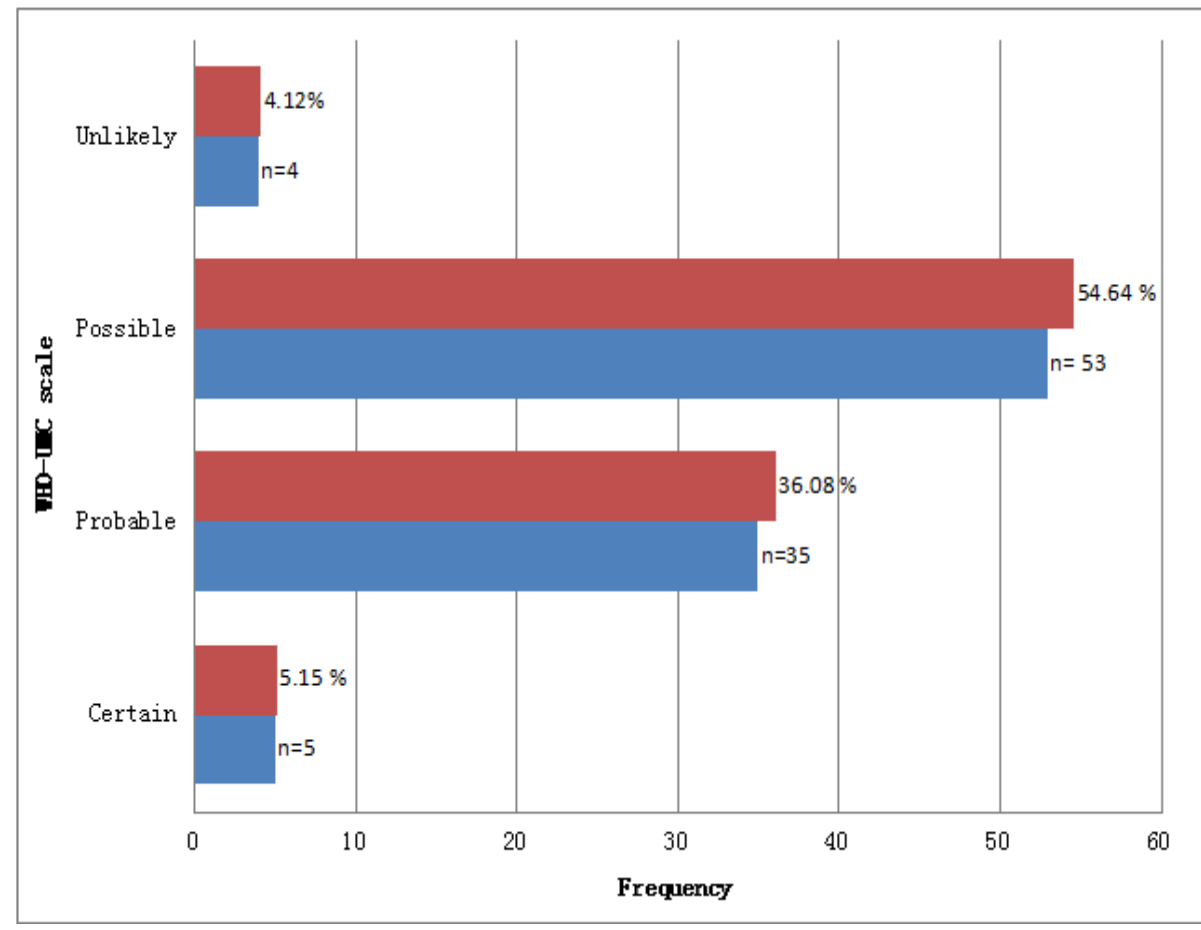

Figure 3: WHO-UMC causality of dermatological ADRs 


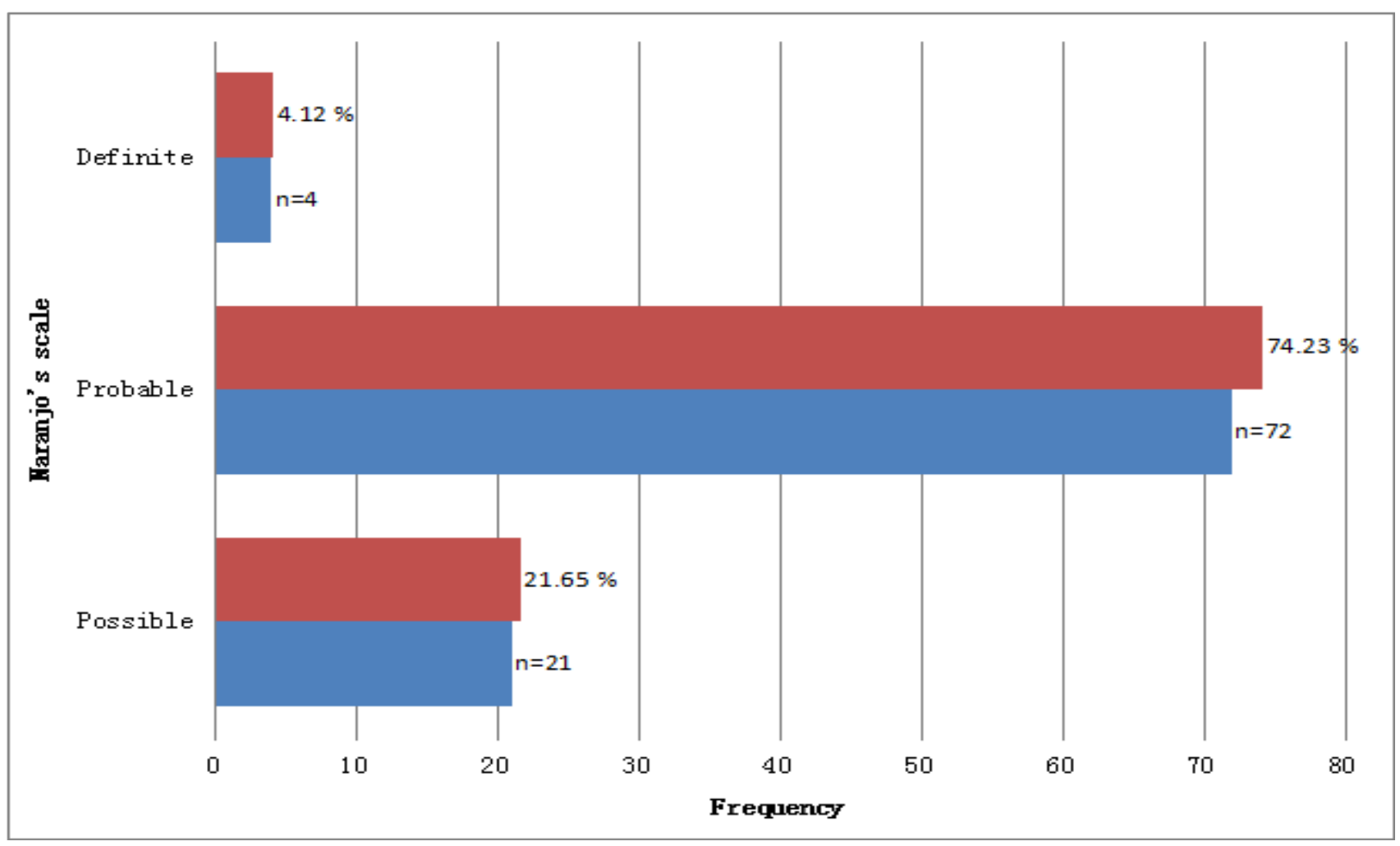

Figure 4: Naranjo'scausality of dermatological ADRs

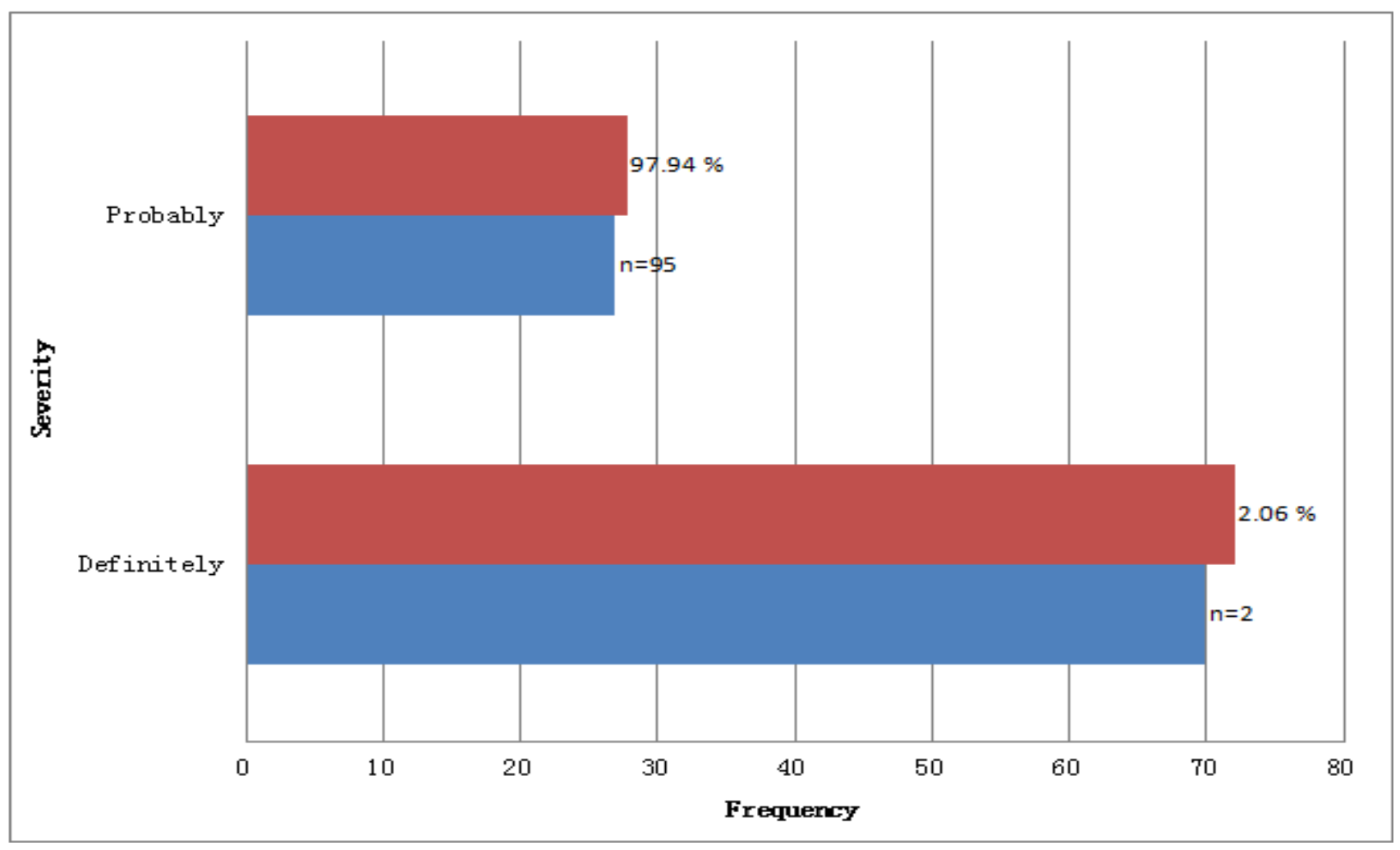

Figure 5: Severity of dermatological ADRs by Hartwig and Siegel's scale 


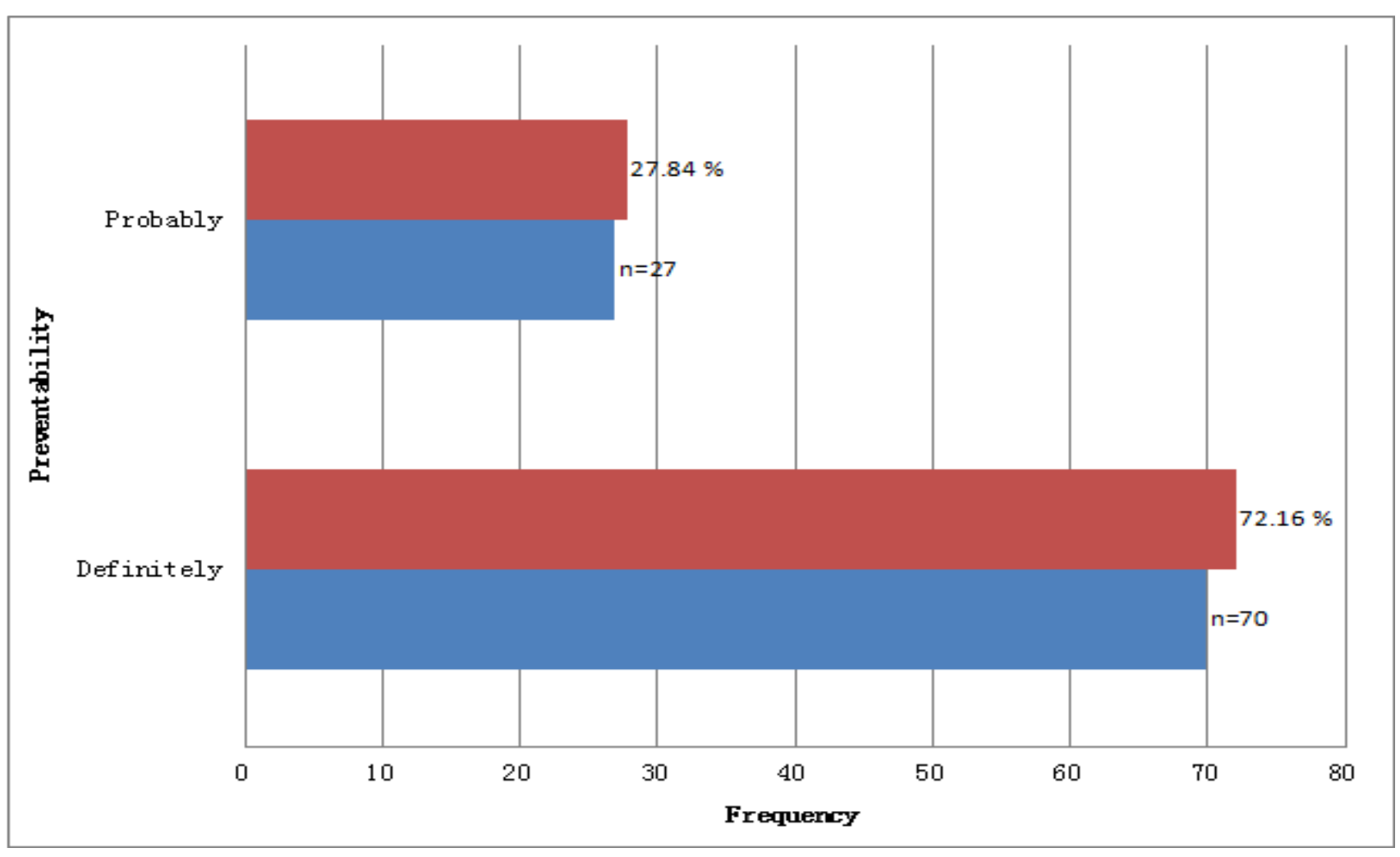

Figure 6: Preventability of dermatological ADRs by Schumock and Thornton's criteria

\section{DISCUSSION}

Drugs are used for treatment and prophylaxis of various disease conditions and are considered as safer drugs when used rationally. Drugs show some Adverse Drug Reactions in various patient conditions. Adverse Drug Reaction monitoring is an essential aspect of therapeutics. However most of the time it is overlooked and not considered important. Even when observed, many would not document and report voluntarily. Establishing pharmacovigilance units in the hospitals has facilitated this activity to a great extent.

This study focused on the pattern of dermatological Adverse Drug Reactions of drug class in the post marketing surveillance studies to find out the effects in a large and diverse population. The suspected ADRs were also notified into National Pharmacovigilance Programme of India as the site where study conducted is one of the ADR monitoring centres at Sheth V S Hospital, Ahmedabad. The direct reporting is also helpful for suspecting dermatological ADRs.

This study revealed the incidence of dermatological ADRs in outdoor patients is $3.78 \%$. Some of previous studies showed incidences of dermatological ADRs in outdoor patients were $2.6 \%, 2.85 \%, 1.6 \%, 7.02 \%$ respectively. ${ }^{1,3,8,9}$
In the present study, findings showed that higher numbers of cases found in males. The same outcome found in some studied having higher male preponderance. ${ }^{10-13}$ Moreover, many studies showed female preponderance. ${ }^{2,3,9,14,15}$ There is no big difference in the numbers of male and female. The reason of higher incidence in present study could be that males are more conscious about any dermatological reaction and treatment of ADR before it gets severe.

In present work, the most suspected ADR were rashes in $20(26.67 \%)$ cases followed by prurit is in $8(10.67 \%)$ cases, urticaria in $8(10.67 \%)$, acne in $6(08.00 \%)$, Fixed Drug Eruption (FDE) in $3(4.00 \%)$ cases. Highly occurring ADR in present study was rashes, which is similar to results obtained in other studies. ${ }^{1,16}$ There were studies conducted in past showing that most common suspected ADR was rash followed by urticaria and/or FDE which are were also observed in the present study., ${ }^{2,11,15-18}$ More number of ADRs was suspected for patients due to the more number of drugs prescribed. It is obvious that the dermatological ADR patterns and the drugs causing various reactions are changing every year which may be due to the emergence of newer molecules and changing trends in the use of drugs. The current study showed 72 non-serious and 2 serious dermatological ADRs. The study conducted by Shah et al at Ahmedabad showed 40 non-serious and 2 serious dermato- 
logical $\mathrm{ADR}^{10}$. The nature of these drugs remained unknown because either the patients brought the drugs in loose, unidentified packs or had consumed them as self-medication.

The most common offending drug classes were antimicrobial agents $42(43.30 \%)$ followed by $26(26.80 \%)$ NSAIDs, $9(26.80 \%)$ were of corticosteroids, 5 (5.15\%) were of anti-epileptic. Chatterjee et al. showed the same higher incidence of suspected drug class which were antimicrobial agents (34.10\%), antiepileptic (32.88\%) and NSAIDs $(21.51 \%)^{3}$. This is quite consistent with present study that most offended drug class was antimicrobials followed by NSAIDs and then antiepileptic. ${ }^{12,19}$ In study at Karmasad showed NSAIDs, antibiotics \& antiepileptic, were reported to produce higher incidence rate, in which two thirds of the patients developing ADRs were due to NSAIDs and antibiotics.?

In present study, paracetamol was highly suspected drug followed by amoxicillin. The same findings also found in study conducted by Ghosh S et al. ${ }^{1}$ Probability of the higher incidence of ADR due to these two drugs could be due to self-medication of such medication without physician consult as it is common among local population or common prescribing pattern.

In present study, one case of atenolol induced psoriasis and one case of hydrochloroquine induced psoriasis was found out. One of the study also proved that long term use of these medications can produce the psoriasis. ${ }^{20,21}$

In our study, 1 case of Toxic Epidermal Necrosis (TEN) and 1 case of Steven Johnson Syndrome (SJS) were reported. In study conducted by Lihite et al ${ }^{22} 2$ cases of TEN and 1 case of SJS were reported whereas Sharma et al. has shown $11.4 \%$ fatal cases of TEN and SJS. ${ }^{11}$

After suspecting ADR, suspected drugs were discontinued or replaced or dose was reduced or medications given for management of ADR. Withdrawal of the suspected drug and antidote such as the use of systemic and topical steroids, antipruritic agents and oral antihistamines were given most commonly for ADR management. The similar finding also presented in studies where drug were being discontinued ${ }^{1,9}$ and higher incidence same class of antidote were given. ${ }^{16}$ It was the dermatologist's discretion, whether the benefit of the drug overweighed the existing ADR and give line of treatment for ADR.

In present study, most of the ADRs in our study were designated as possible $(54.64 \%)$ or probable $(36.08 \%)$ in WHO-UMC causality assessment which is quite consistent with Shah et al $(69 \%)$. Among them, possible ADRs were highly observed. Few studies showed higher cases of probable $73.2 \%, 80.35 \%$ respectively. ${ }^{3,9}$ The percentage of dermatological ADRs falling in category of definite (certain) is very low $(5.15 \%)$ comparing to other category which is also found low in few studies $\left(11.42 \%, 1.7 \%\right.$ respectively). ${ }^{9,12}$ In our study according to WHO-UMC causality assessment, NSAIDs caused a certain type of ADR compared to other type of ADR.

In present study according to Naranjo's causality scale, 4 ADRs were definite, 72 ADRs were probable, 21 ADRs were possible. The study at Guwahati by Lihite et al showed higher cases of probable ADRs similar to the present study. ${ }^{8}$

Comparison of strength of agreement between different scales of causality assessment (WHO-UMC causality assessment and Naranjo's causality scale) is done by using Cohen's kappa test. It showed that full agreement was not found between any of two scales of causality assessment. Positive but poor agreement based on kappa values was seen between WHO and Naranjo's causality comparison. This was due to different definitions of causality criteria for assessing adverse drug reactions.

In present study, only 2 ADRs were of mild severity and the rest of all 95 ADRs were of moderate severity. A majority of ADRs were categorized as moderately severe while few cases of severe in nature, and similar findings are reported in other studies. ${ }^{1,10}$. When ADRs were suspected at OPD of dermatology, the medications were always given for the management of ADRs. Despite of these, in two cases of mild severity, the drugs were only discontinued.

Result of present study showed most of ADRs were definitely preventable. These findings were similar to study conducted in past. ${ }^{8,11}$

On evaluation of chances of preventability of ADRs, all the ADRs may have been preventable, if proper precaution were taken like patients should carry drug list indicating which drugs they are allergic to at time of hospital visit to avoid reactions again. Preventability of ADR with unlikely WHO-UMC causality of ADR showed definitely preventable ADR compared to probably preventable ADR of other category of WHOUMC causality terms.

The limitations of the study were the exact incidence of dermatological ADRs which may be difficult to obtain owning to fact that the researcher must rely on patient for reporting of ADR and drug details. In our study reports from dermatology OPD were considered, excluding dermatological ADRs reported from other departments of hospital, small sample size, confined to the Outpatient Department of dermatology for a short period of three months. Due to lack of followup, exact outcome of ADR was not obtained in all patients. Moreover, ADRs of recently introduced drugs 
could also not be generated. Dechallenge and rechallenge were not done in many cases after identification of ADRs until happened naturally.

There are few recommendations for work in this area is for determination of exact incidence, study may carry out for longer duration of time with large patient population. Further studies are required to determine the prevalence, predictors and risk factors of the dermatological ADRs in order to improve the drug safety. For patients who don't come back for follow up, some steps should be taken to consider them and give more attention for better patient care. Patients' awareness regarding OTC drugs and self-medications should also be strengthened.

\section{CONCLUSION}

From the results revealed from this study it was concluded that dermatological Adverse Drug Reaction was a common occurrence and awareness for them is essential for diagnosis and prevention. The dermatological ADR varied in their appearance, duration, causality, severity, and preventability. Antimicrobial agents and NSAIDs were the most common implicated drug class. Depending upon nature of ADR, actions against suspected drug along with symptomatic treatments were given whenever found significant. Most of ADR gets unreported due to lack of interest in ADR monitoring and reporting at hospital settings. By present piece of work, pharmacist contributed patient safety and rational use of drug by assessing, reporting and treating ADRs. The healthcare system should promote the spontaneous reporting of dermatological adverse drug reaction to pharmacovigilance centers for ensuring drug safety.

\section{ACKNOWLEDGEMENT}

The authors are thankful to Board of Management of Sheth V. S. Hospital, for permitting to carry out the study. We appreciate the help received from Dr. Ranjan C. Raval, Head of Department of Dermatology and staff of Out Patient Department of Dermatology, Sheth V. S. Hospital, Ahmedabad.

\section{CONFLICTS OF INTEREST}

No conflict to disclose.

\section{REFERENCES}

1. Ghosh S, Acharya L, Rao P. Study and evaluation of various cutaneous adverse drug reactions in kasturba hospital, Manipal. Indian J Pharm Sci. 2006 Mar; 68(2): 212-15.
2. Sudershan V, Siddiqua S, Aruna D, Manmohan, Ramesh S, Yasmeen N. Cutaneous adverse drug reactions in a tertiary care hospital. Der Pharmacia Lettre. 2011; 3(6): 210-17.

3. Chatterjee S, Ghosh AP, Barbuiya J, Der SK. Adverse cutaneous drug reaction: a one year survey of a dermatology outpatient clinic of a tertiary care hospital. Indian J Pharmacol. 2006 Dec; 36(6): 429-31.

4. Mann RD, Andrews EB. Pharmacovigilance. England: John Wiley \& Sons, Ltd; 2002.

5. Shamna M, Dilip C, Ajmal M, Mohan P, Shinu C, Jafer CP, et al. A prospective study on Adverse Drug Reactions of antibiotics in a tertiary care hospital. Sau Pharma J. 2013 Jun; 1-6. 1-6. Available online: July 2013; Accessed online at URL: http://www.sciencedirect.com/science/article/pii/S1319016413000765

6. Grootheest K, Olsson S, Couper M, Berg LJ. Pharmacists' role in reporting adverse drug reactions in an international perspective. Pharmacoepidemiol and drug saf. 2002 Apr; 11: 205-10.

7. Sriram S, Ghasemi A, Ramasamy R, Devi M, Balasubramanian R, Ravi TK, et al. Prevalence of adverse drug reactions at a private tertiary care hospital in south India. J Res Med Sci. 2011; 16(1): 16-25.

8. Lihite RJ, Lahkar M. A Study on Cutaneous Adverse Drug Reactions in ADR Monitoring Centre of Tertiary Care Hospital, Guwahati. Journal of Applied Pharmaceutical Science. 2013 Mar; 3(03): 78-81.

9. Suthar J, Desai S. A study of Adverse Cutaneous Drug Reactions in Outdoor Patients attending to Skin \&V.D. Department of Shree Krishna Hospital, Karamsad. Int J Res Pharm Biomed Sci. 2011 Jan; 2(1): 274-9.

10. Shah SP, Desai MK, Dikshit RK. Analysis of Cutaneous Adverse Drug Reactions at a Tertiary Care Hospital - a Prospective Study. Trop J Pharm Res. 2011 Aug; 10(4): 517-22.

11. Sharma VK, Sethuraman G, Kumar B. Cutaneous adverse drug reactions: Clinical pattern and causative agents-A six-year series from Chandigarh, India. J Postgrad Med. 2001; 47: 95-9.

12. Sushma M, Noel MV, Ritika MC, James J, Guido S. Cutaneous adverse drug reactions: a 9-year study from a South Indian Hospital. Pharmacoepidemiol Drug Saf. 2005 Aug; 14(8): 567-70.

13. Pudukadan D, Thappa DV. Adverse cutaneous drug reactions: Clinical pattern and causative agents in a tertiary care center in South India. Indian J Dermatol Venereol Leprol. 2004; 70(1): 20-4.

14. Nandha R, Gupta A, Hashmi A. Cutaneous adverse drug reactions in a tertiary care teaching hospital: A North Indian perspective. Int $\mathrm{J}$ of Appl and Bas Med Res. Jan 2011; 1(1): 50-3.

15. Mbuagbaw J, Egbembah Mbuagbaw L, Chiabi A, Bisseck C, Nkam M. Mucocutaneous Adverse Drug Reactions In A Hospital Setting In Cameroon. The Int J Dermatology. 2007; 6(2).

16. Dubey AK, Prabhu S, Shankar PR, Subish P, Prabhu MM, Mishra P. Dermatological adverse drug reactions due to systemic medications - A review of literature. J Pak Asso Dermat. 2006; 16(Issue Missing): 28-38.

17. Jena M, Mishra S, Panda M, Mishra SS. Cutaneous Adverse Drug Reaction Monitoring Of Different Drugs In Dermatology OPD Of A Tertiary Care Teaching Hospital. Int J Cur Res Rev. 2013 Apr; 5(7): 77-82.

18. Anjaneyan G, Rajat Gupta, Rita Vora. Clinical study of adverse cutaneous drug reactions at a rural based tertiary care centre in Gujarat. Nat J Phys Pharm Pharmacol. 2013; 3(2): 129-36.

19. Brahma DK, Sangma KA, Lynrah KG, Marak MD, Wahlang JB, Bhattacharyya $\mathrm{H}$, et al. Adverse cutaneous drug reactions: A one year survey at dermatology outpatient clinic in a tertiary care hospital. Inter J Pharm World Res. 2012 Mar; 3(2): 1-9.

20. Tsankov N, Angelova I, Kazandjieva J. Drug-Induced Psoriasis. Am J Cli Dermat. 2000 May; 1(3): 159-65.

21. Brauchli YB, Jick SS, Curtin F, Meier CR. Association between beta-blockers, other antihypertensive drugs and psoriasis: population-based case-control study. Brit J Dermat. 2008; 158 (6): 1299-307.

22. Agbabiaka TB, Savovi J, Ernst E. Methods for Causality Assessment of Adverse Drug Reactions A Systematic Review. Drug Saf. 2008; 31(1): 21-37. 